\title{
On a Constitutive Material Model to Capture Time Dependent Behavior of Cortical Bone
}

\author{
Anders Halldin 1,2*, Mats Ander', Magnus Jacobsson ${ }^{1,2}$, Stig Hansson² \\ ${ }^{1}$ Department of Prosthodontics, Faculty of Odontology, Malmö University, Malmö, Sweden \\ ${ }^{2}$ DENTSPLY Implants, Mölndal, Sweden \\ ${ }^{3}$ Department of Applied Mechanics, Chalmers University of Technology, Göteborg, Sweden \\ Email: ${ }^{*}$ anders.halldin@mah.se
}

Received 3 October 2014; revised 2 November 2014; accepted 24 November 2014

Copyright (C) 2014 by authors and Scientific Research Publishing Inc.

This work is licensed under the Creative Commons Attribution International License (CC BY). http://creativecommons.org/licenses/by/4.0/

(c) (i) Open Access

\section{Abstract}

It is commonly known that cortical bone exhibits viscoelastic-viscoplastic behavior which affects the biomechanical response when an implant is subjected to an external load. In addition, long term effects such as creep, relaxation and remodeling affect the success of the implant over time. Constitutive material models are commonly derived from data obtained in in vitro experiments. However during function, remodeling of bone greatly affects the bone material over time. Hence it is essential to include long term in vivo effects in a constitutive model of bone. This paper proposes a constitutive material model for cortical bone incorporating viscoelasticity, viscoplasticity, creep and remodeling to predict stress-strain at various strain rates as well as the behavior of bone over time in vivo. The rheological model and its parameters explain the behavior of bone subjected to longitudinal loading. By a proper set of model parameters, for a specific cortical bone, the present model can be used for prediction of the behavior of this bone under specific loading conditions. In addition simulation with the proposed model demonstrates excellent agreement to in vitro and in vivo experimental results in the literature.

\section{Keywords}

Cortical bone Viscoelastic-Viscoplastic Creep Remodeling Constitutive Model

\section{Introduction}

The main function of bone is to carry load. An external load applied to bone induces strains of different magnitudes, depending on loading condition, geometry and material behavior of the bone. Numerous investigations

\footnotetext{
${ }^{*}$ Corresponding author.
} 
have been conducted to examine the behavior of bone under loading [1]-[14]. Research has found that when cortical bone is loaded below yield load, the initial mechanical response is linear and can be described by Hooke's law. Bone constitutes a hierarchical structure, where all structural levels determine the macro material properties [15] [16] and contains of three major components, collagen, mineral and body fluid, that contribute to the mechanical behavior. Currey [17] finds that Young's modulus is correlated to the amount of hydroxyapatite, where increased content of the mineral results in higher Young's modulus. If the load is increased, the bone reaches a yield point with an associated yield strain. Currey [17] further finds that bone seems to yield at a particular strain level of 0.0036 - 0.012 rather than at a particular stress level, with lower strain values for high Young's modulus and high mineral content. Several researchers have found that bone exhibits viscoelastic properties both in tension and compression [1] [2] [4] [18]-[21]. In these studies the material stiffness represented by Young's modulus increased with increased strain rate but for the yield strain the results were not coherent. The results of Crowninshield and Pope [4] indicate that higher strain rate gives higher yield strain in tension. Similar findings were obtained by Currey [22] and Melnis and Knets [18]. However the results of compression test by McElhaney [1] indicate that for low strain rate, the yield strain level is independent of strain rate but decreases for high strain rates. Hansen et al. [20] reported decreased yield strain levels for increased strain rate in tension. This contradiction in results may reflect different species, specimen sampling, specimen preparation and testing procedures. Currey [23] finds that the homogenized bone properties are species specific. Melnis and Knets [18] conclude that the mechanical properties and viscoelastic behavior of bone material are significantly dependent on moisture content. It has also been found that the age of the bone affects its porosity which in turn affects the mechanical properties such as ultimate stress, ultimate strain, and yield stress [24]. Beyond the yield strain, post yield strain occurs in the bone. Post yield strain reflects damage of the material caused by micro cracks and/or internal slip between the mineral and collagen that degrades the material until failure [13] [25]. Studies have demonstrated that the strain rate affects the evolution of post yield strain, where lower strain rate exhibits an increase of post yield strain before failure [1] [4] [25]. Beyond yield strain, bone may withstand increased loading due to hardening before failure [1] [4] [18]. It has also been found that bone demonstrates relaxation over time [26]. According to Iyo et al. [26] the relaxation phenomena consists of two different processes: one fast process (relaxation time in order of $10^{2} \mathrm{~s}$ ) explained by relaxation of the collagen matrix and one slower relaxation (relaxation time in order of $10^{6} \mathrm{~s}$ ) related to the higher order structure of the bone. Several studies have shown that bone exhibits creep phenomena including a viscoelastic creep that recovers after unloading and a creep that remains after unloading [27]-[30]. Bone is a living material and it is difficult to perform strength tests in vivo. Therefore most studies have been performed in vitro on dead bone. However a few in vivo tests exist that can be used to extract the mechanical properties of bone [8] [31] [32]. Perren et al. [8] installed compression plates in sheep tibia in vivo and measured the development of longitudinal forces over time. They concluded that an initial decrease in axial force is related to the viscoelastic properties of bone and that a subsequent linear decrease in pressure is related to remodeling. Similar findings have been reported by Cordey et al. [32] and by Blumlein et al. [31]. Generally the remodeling rate is species dependent [33]. To capture the behavior of cortical bone subjected to various loading rate it is essential to have a constitutive material model that captures the stressstrain relationship for different strain rates. Johnson et al. [11] developed a viscoelastic-viscoplastic constitutive model that describes the stress-strain relationship for different strain rates. Their model demonstrates excellent agreement with published experimental tests results. However the Johnson et al. [11] model does not contain a remodeling term for biological reduction of the initiated pre-stress over time. In addition it does neither model relaxation nor creep. Furthermore, it does not reflect the hardening effect implying that the stress may increase during post yield strain. When an oversized implant is inserted into bone it induces static strains that create static stresses in the bone that gradually decline due to relaxation and remodeling. In addition, if a constant load is applied strains increase in time due to creep. The objective of the present study is to develop a constitutive model for cortical bone that captures the mechanical behavior of the bone subjected to a longitudinal load. The proposed constitutive model with calibrated model parameters should predict the stress strain, relaxation and creep behavior observed in the in vivo and in vitro experiments.

\section{Theory}

This work proposes a viscoelastic-viscoplastic material model with a remodeling term to describe the relationship between stress and strain in vivo. This model has similarities to that of Johnson et al. [11] but also captures 
hardening, relaxation, creep and remodeling behavior. The model is illustrated by the rheological model according to Figure 1.

It consists of three different components: one viscoelastic, one viscoplastic, and one remodeling component. The individual components might contain several parts, contributing to the specific behavior of bone.

The total strain according to Figure 1 can be defined as follows:

$$
\varepsilon=\varepsilon_{i}^{e}+\varepsilon_{i}^{v}+\varepsilon^{p}+\varepsilon^{r}
$$

The parameters describing the material model (Table 1) are calibrated by use of experimental results, representing homogenized bone, found in the literature (Table 2).

The relationship between stress and strain for each component, respectively, is derived by the use of the dissipation inequality according to the second law of thermodynamics.

\subsection{Viscoelastic Component}

During function, short term loads with different loading rates are applied which affect the bone differently due to the viscoelastic properties. To predict viscoelastic creep, relaxation and stiffness for different strain rates the proposed model consists of one spring element and four Maxwell elements in parallel (Figure 1).

The strain rate $\dot{\varepsilon}_{i}^{v}$ in the individual dashpot $(i)$, of the Maxwell element, with associated viscosity $v_{i}$ is defined as:

$$
\dot{\varepsilon}_{i}^{v}=\frac{\sigma_{i}}{v_{i}}
$$

\subsection{Viscoplastic Component}

The viscoplastic component contains a plastic pad, a dashpot and a spring in parallel. The plastic pad is activated by stresses beyond a triggering stress resulting in permanent strain. The dashpot captures the increase of stress with an increase in strain rate [1] and the spring mimics hardening of the material causing an increase in stress at post yield strain [1] [4] [18]. The viscoplastic component has similarities with the one in Garcia's model [12] but does not include a damage criterion. However a further development, including Garcia's [12] damage criterion to the spring in the viscoplastic component, may be possible. The constitutive equations for the viscoplasticcomponent originate from Perzyna [34] [35] and are further described in Ottosen and Ristinmaa [36].

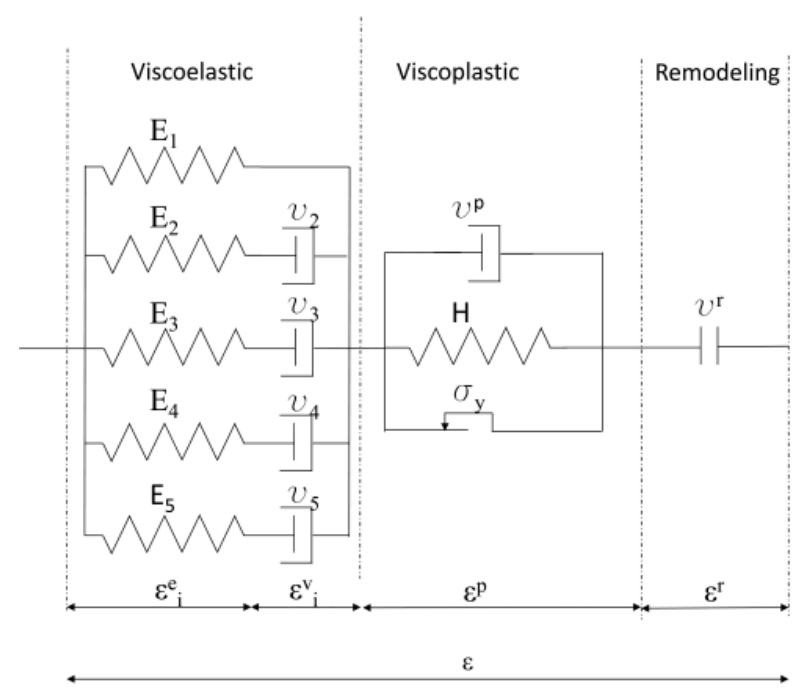

Figure 1. Illustration of the rheological model for the proposed constitutive material model of vital cortical bone in longitudinal direction. The model consists of three different components (viscoelastic, viscoplastic and remodeling) to capture stressstrain relationship, relaxation, remodeling and creep behavior. 
Table 1. Symbols used in the modeling and definitions.

\begin{tabular}{cc}
\hline Parameter & Definition \\
\hline$\varepsilon_{i}^{e}$ & Elastic strain in spring $(i)$ \\
$\varepsilon_{i}^{v}$ & Viscoelastic strain in dashpot $(i)$ \\
$\varepsilon^{p}$ & Plastic strain \\
$\varepsilon^{c r}$ & Permanent creep strain \\
$\varepsilon^{r}$ & Remodeling strain \\
$E_{1-5}$ & Elastic stiffness \\
$u_{2-5}$ & Viscosity in the elastic component \\
$H$ & Hardening \\
$\mathrm{np}$ & Plastic stress exponent \\
$s_{y}$ & Yield stress \\
$u_{p}$ & Viscosity in the plastic component \\
$\sigma_{c}^{p}$ & Arbitrary reference stress \\
$\lambda$ & Plastic multiplier \\
$R$ & Remodeling \\
\hline
\end{tabular}

Table 2. Overview of experimental studies referred to in the present study.

\begin{tabular}{|c|c|c|c|c|c|c|}
\hline \multicolumn{7}{|c|}{ Aspects of the mechanical behavior of bone } \\
\hline & & Stress strain & Creep & Relaxation & Remodeling & Comment \\
\hline \multirow{5}{*}{ 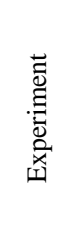 } & Melnis and Knets [18] & Tension & & & & In vitro \\
\hline & McElhaney [1] & Compression & & & & In vitro \\
\hline & Crowninshield and Pope [4] & Tension & & & & In vitro \\
\hline & Melnis et al. [27] & & Tension & & & In vitro \\
\hline & Perren et al. [8] & & & Compression & Compression & In vivo \\
\hline 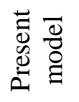 & $\begin{array}{l}\text { Parameters that were calibrated to } \\
\text { capture the mechanical behavior } \\
\text { found in experiments }\end{array}$ & $\begin{array}{c}E_{1}-E_{5} \\
u_{4} \text { and } u_{5} \\
s_{y}, H \text { and } u_{p}\end{array}$ & $E_{3}$ and $u_{3}$ & $E_{2}$ and $u_{2}$ & $u_{r}$ & Simulation \\
\hline
\end{tabular}

The yield function $\phi$, according to Ottosen and Ristinmaa [36], is defined as

$$
\phi=|\sigma|-\left(\sigma_{y}+H\right)
$$

where the yield evolves when $\phi \geq 0$.

The plastic strain rate is defined as

$$
\dot{\varepsilon}^{p}=\lambda \frac{\partial \phi}{\partial \sigma}=\lambda \cdot \operatorname{sign}(\sigma)
$$

where

$$
\lambda=\frac{E_{\text {tot }}}{v^{p}} \eta(\phi)
$$

An overstress function $\eta(\phi)$ is defined according to the Norton creep power law [37]: 


$$
\eta(\phi)=\left(\frac{\langle\phi\rangle}{\sigma_{c}^{p}}\right)^{n p}
$$

The stress $\sigma_{c}^{p}$ is an arbitrary reference stress. It is postulated that: $\sigma_{c}^{p}=\sigma_{y}+H$.

\subsection{Remodeling Component}

The linear decrease in force in Perren's et al. [8] in vivo experiment is interpreted as a reduction in stress due to remodeling of bone. In the present study the reduction of stress is modeled as a constant reduction of strain over time and the remodeling component is therefore expressed in terms of a constant strain rate:

$$
\dot{\varepsilon}^{r}=R \cdot \operatorname{sign}(\sigma)
$$

In the proposed model we define a remodeling parameter $(R)$ to:

$$
R=\frac{\sum E_{i}}{v_{r}}
$$

\subsection{Differential Equation for the Proposed Bone Model}

By adding the different components into the rheological model, the differential equation for each spring-dashpot-combination is derived.

Spring 1

$$
\dot{\sigma}_{1}=E_{1} \dot{\varepsilon}-E_{1} R \operatorname{sign}(\sigma)-E_{1} \lambda \operatorname{sign}(\sigma)
$$

Spring 2 - 4

$$
\dot{\sigma}_{i}=E_{i} \dot{\varepsilon}-\frac{E_{i}}{v_{i}} \sigma_{i}-E_{i} R \operatorname{sign}(\sigma)-E_{i} \lambda \operatorname{sign}(\sigma)
$$

\subsection{Calibration of Model Parameters}

The magnitude of the viscoelastic, viscoplastic, relaxation, creep and remodeling parameters were obtained by fitting the model simulations to experimental results [1] [4] [8] [18] [27] by minimizing the error. The minimized error was found by using the constrained nonlinear optimization function (FMINSEARCHCON) available in MATLAB.

\subsection{Viscoelastic and Viscoplastic Stress-Strain Behavior}

The viscoelastic and viscoplasticstress-strain behavior of cortical bone is reported in Crowninshield and Pope [4], McElhaney [1] and Melnis and Knets [18]. The simulations, by use of the proposed constitutive model with the calibrated parameter values, mimic the stress strain curves in these in vitro experimental studies.

\subsection{Relaxation and Remodeling Behavior}

The relaxation and remodeling behavior of cortical bone was identified using three in vivo data sets of reduction in force with time obtained from Perren et al. [8]. The proposed model presents relaxation as a reduction of stress with time. Therefore the axial force was converted to stress by assuming a cross sectional area of $160 \mathrm{~mm}^{2}$ for one sheep tibia. The other two sheep tibiae cross sectional areas were thereafter set to 186 and $290 \mathrm{~mm}^{2}$ respectively resulting in the same remodeling rate for the different sheep. The measurements in Perren et al. [8] started $3 \mathrm{~h}$ after the initiation of bone compression. Therefore the initial (at $0 \mathrm{~s}$ ) strain level was adjusted to fit the measurements at $3 \mathrm{~h}$ in Perren et al. [8].

\subsection{Reversible and Irreversible Creep Behavior}

Creep behavior was identified using creep curves from the experiments of Melnis et al. [27]. Four different 
magnitudes of constant stress for the individual stress-strain tests were used $(20 \%, 30 \%, 40 \%$ and $50 \%$ of ultimate stress $\left[s_{u}\right]$ ). The ultimate stress (in Melnis and Knets [18] $s_{u}=112 \mathrm{MPa}$, in McElhaney [1] $s_{u}=144$ MPa and Crowninshield and Pope [4] $s_{u}=141 \mathrm{MPa}$ ) was determined by use of stress-strain curves at strain rates of $0.001 \mathrm{~s}^{-1}$ respectively. The constant stress was applied during 12,000 s and then released. For simulation purposes the stress was ramped up to a constant level during $1 \mathrm{~s}$ and ramped down during $1 \mathrm{~s}$.

\section{Results}

Applying appropriate parameters values the predictions of the mechanical behavior of the bone agrees well with the results in experimental tests according to Figures 2-5.
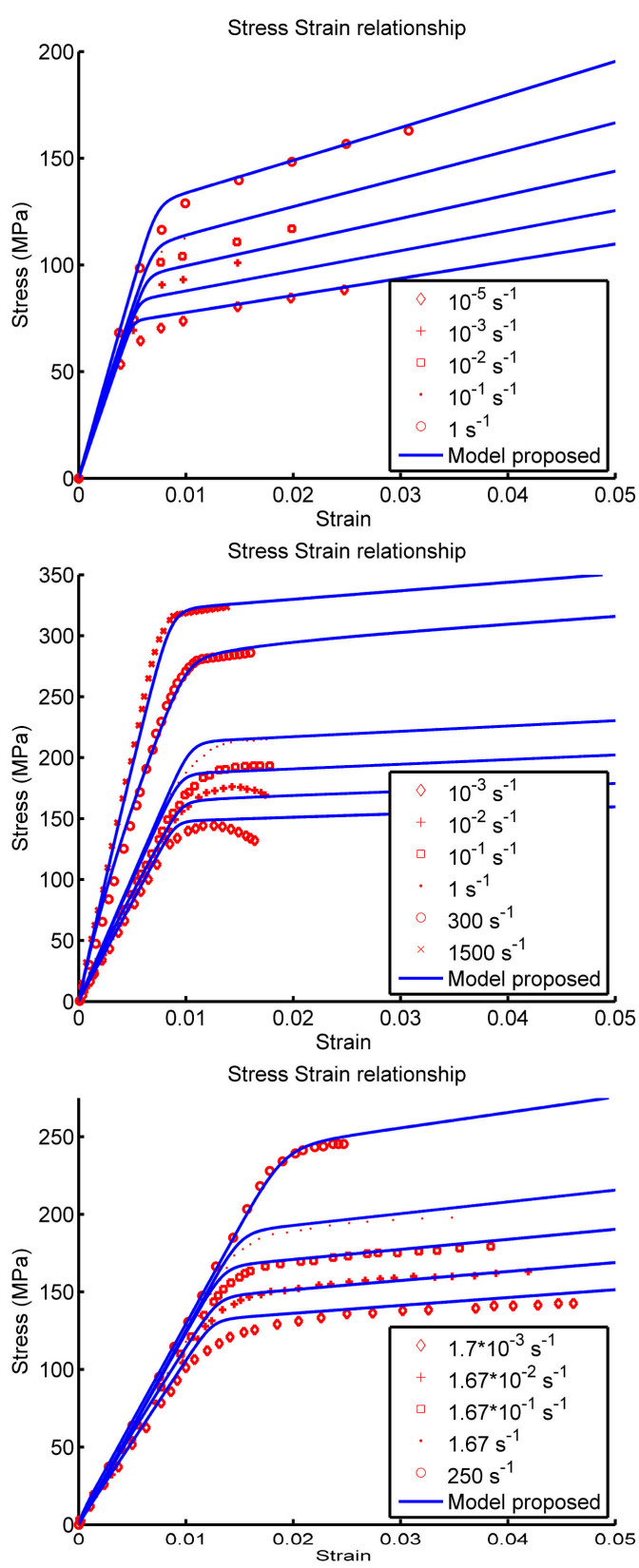

Figure 2. Stress-strain curves predicted by the proposed model with corresponding experimental data for (a) Melnis and Knets [18] (b) McElhaney [1] and (c) Crowninshield and Pope [4]. 

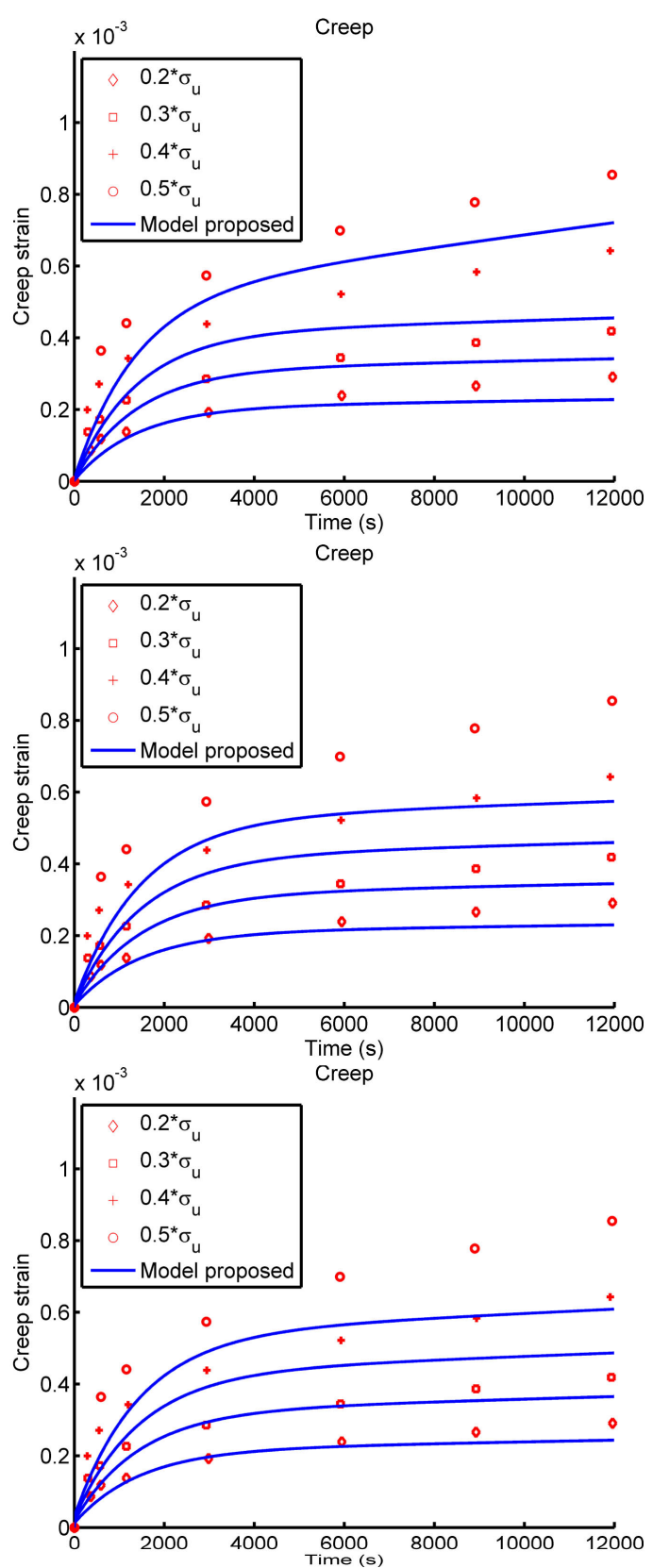

Figure 3. Prediction of creep behavior by the proposed model for the stress-strain tests of (a) Melnis and Knets [18] (b) Mc Elhaney [1] and (c) Crowninshield and Pope [4] with corresponding experimental data from Melnis et al. [27].

The parameters for the viscoelastic component are presented in Table 3.

It seems that individual spring stiffness $E_{1}, E_{2}, E_{3}, E_{4}$, and $E_{5}$, are $25 \%-28 \%, 11 \%-12 \%, 3 \%-5 \%, 9 \%-10 \%$ and $48 \%-50 \%$, respectively of total Young's modulus (sum $\left(E_{1}\right.$ to $\left.E_{5}\right)$ ) regardless of stress strain test (Table 4).

The values obtained for the viscosity parameter $u_{2}$ are in the same range when fitting the model to the experimental results of Melnis and Knets [18], McElhaney [1] and Crowninshield and Pope [4], representing relaxation times $t_{2}$ of 3.3, 3.9 and 4.1 days respectively (Table 3). The viscosity parameter $u_{3}$ represents fast relaxation with relaxation times $t_{3}$ in the range of $1200-1330 \mathrm{~s}$ (Table 3 ). The viscosity parameters $u_{4}$ and $u_{5}$ represent even faster relaxation with relaxation times $t_{4}$ and $t_{5}$ in the range of $100-400 \mathrm{~ms}$ and $1-20 \mu$ s respectively 

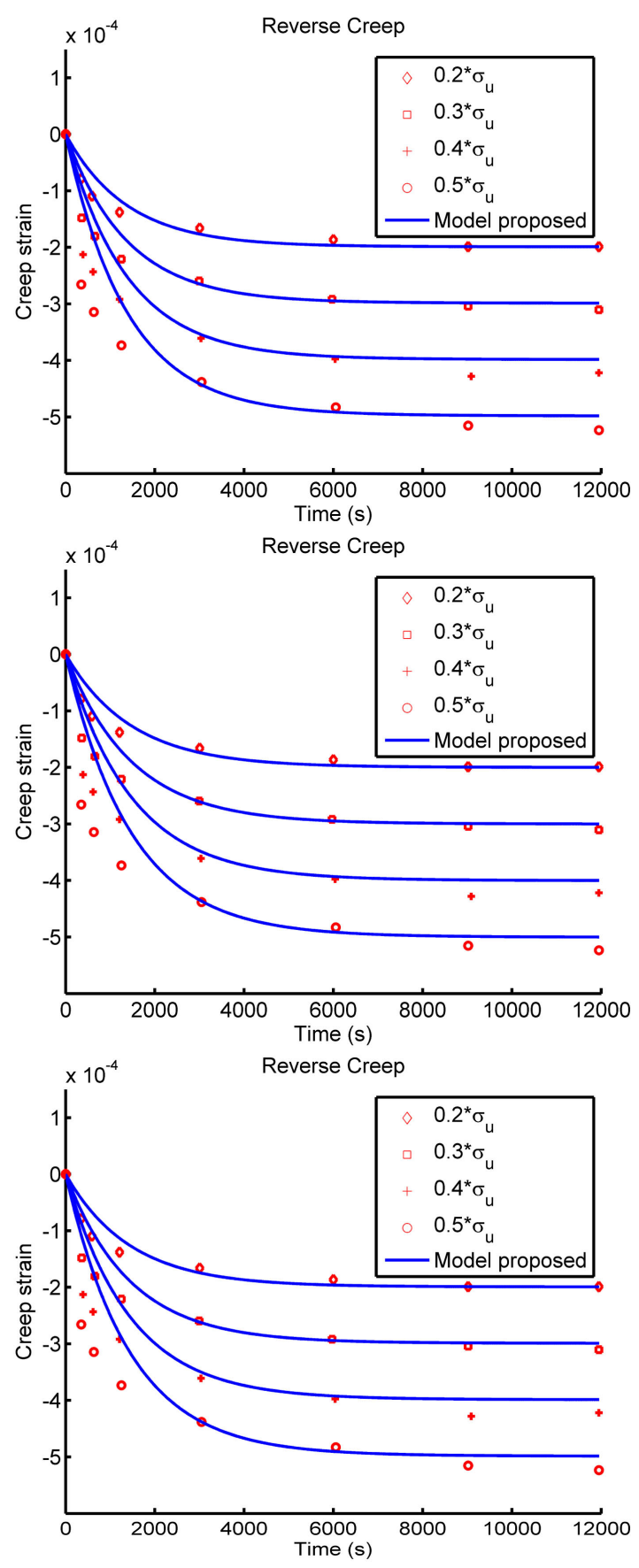

Figure 4. Prediction of reverse creep behavior by the proposed model for the stress-strain tests of (a) Melnis and Knets [18] (b) Mc Elhaney [1] and (c) Crowninshield and Pope [4] with corresponding experimental data from Melnis et al. [27].

(Table 3). The values of the individual parameters obtained for the viscoplastic component, when fitting the model to the experimental results of Melnis and Knets [18], McElhaney [1] and Crowninshield and Pope [4], clearly differ (Table 5).

To capture the stress strain behavior for all strain rate experiments $s_{y}$ must be in the range of the yield point for the stress strain curve for the lowest strain rate. In the present model the value of $s_{y}$ shall be seen as a triggering value for the viscoplastic behavior for all strain rates. However to significantly evolve plastic strain 

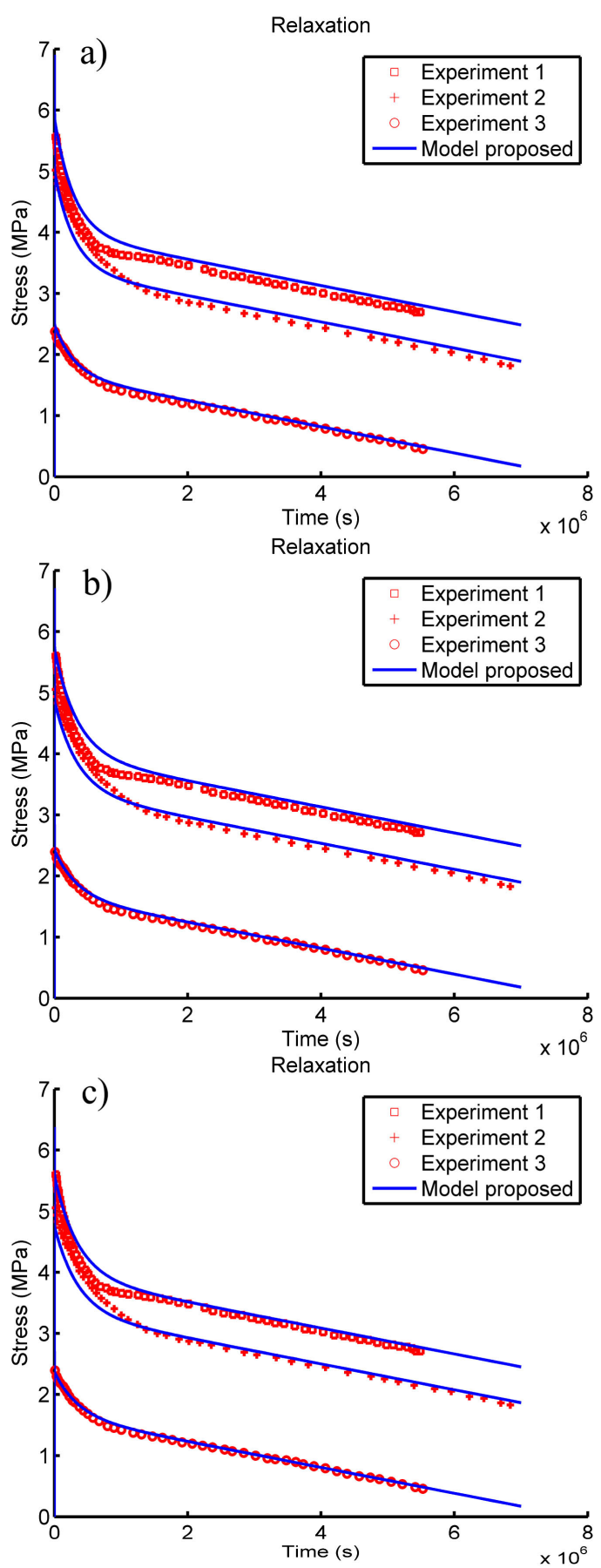

Figure 5. Prediction of relaxation and remodeling behavior by the proposed model for the stress-strain tests of (a) Melnis and Knets [18] (b) McElhaney [1] and (c) Crowninshield and Pope [4] with corresponding experimental data from Perren et al. [8].

(representing material yield) for increased strain rate increased stress is required. The stress-strain test (Figure 2(a)) of Melnis and Knets [18] resulted in a higher value of the hardening coefficient $H$ compared to the other stress-strain tests (Figure 2(b), Figure 2(c)) [1] [4]. In addition the magnitude of the yield stress value is higher for McElhaney's [1] compressive test compared to those of the tensile tests [4] [18]. The parameter value obtained for the remodeling $(R)$ component is presented in Table 6. 
Table 3. Parameters, for the individual stress-strain tests, of the viscoelastic component according to Figure 1 with time constants $t$. The parameters are calibrated by means of the least square method to fit stress-strain, relaxation, remodeling and creep experimental data..

\begin{tabular}{cccc}
\hline \multirow{2}{*}{ Model parameter } & \multicolumn{3}{c}{ The magnitude of the viscoelastic parameters } \\
\cline { 2 - 4 }$E_{1}[\mathrm{Mpa}]$ & Melnis and Knets [18] & McElhaney [1] & Crowninshield and Pope [4] \\
$E_{2}[\mathrm{Mpa}]$ & 8989 & 10,175 & 6904 \\
$E_{3}[\mathrm{Mpa}]$ & 4167 & 4355 & 2828 \\
$E_{4}[\mathrm{Mpa}]$ & 1797 & 1678 & 739 \\
$E_{5}[\mathrm{Mpa}]$ & 3587 & 4221 & 2065 \\
$u_{2}[\mathrm{Mpa} \mathrm{s}]$ & 17,890 & 20,729 & 11,699 \\
$u_{3}[\mathrm{Mpa} \mathrm{s}]$ & $1.2 \mathrm{E}+09$ & $1.5 \mathrm{E}+09$ & $9.9 \mathrm{E}+08$ \\
$u_{4}[\mathrm{Mpa} \mathrm{s}]$ & $2.2 \mathrm{E}+06$ & $2.2 \mathrm{E}+06$ & $9.8 \mathrm{E}+05$ \\
$u_{5}[\mathrm{Mpa} \mathrm{s}]$ & $5.1 \mathrm{E}+02$ & $8.3 \mathrm{E}+02$ & $6.9 \mathrm{E}+02$ \\
$t_{2}[\mathrm{~s}$ (days) & $3.8 \mathrm{E}-01$ & $2.6 \mathrm{E}-01$ & $1.6 \mathrm{E}-02$ \\
$t_{3}[\mathrm{~s}]$ & $2.9 \mathrm{E}+05(3.3)$ & $3.4 \mathrm{E}+05(3.9)$ & $3.5 \mathrm{E}+05(4.1)$ \\
$t_{4}[\mathrm{~ms}]$ & 1203 & 1313 & 1330 \\
$t_{5}[\mu \mathrm{s}]$ & 141 & 197 & 334 \\
\hline
\end{tabular}

Table 4. Contributions in \% to the total Young's modulus of the springs in the viscoelastic component, for the individual stress-strain tests, indicating the same distribution independent of test.

\begin{tabular}{cccc}
\hline Ratio & Melnis and Knets [18] & McElhaney [1] & Crowninshield and Pope [4] \\
\hline$E_{1} / E_{\text {tot }}$ & $25 \%$ & $25 \%$ & $28 \%$ \\
$E_{2} / E_{\text {tot }}$ & $11 \%$ & $11 \%$ & $12 \%$ \\
$E_{3} / E_{\text {tot }}$ & $5 \%$ & $4 \%$ & $3 \%$ \\
$E_{4} / E_{\text {tot }}$ & $10 \%$ & $10 \%$ & $9 \%$ \\
$E_{5} / E_{\text {tot }}$ & $49 \%$ & $50 \%$ & $48 \%$ \\
\hline
\end{tabular}

Table 5. Parameters for the stress-strain tests of the viscoplastic component according to Figure 1.

\begin{tabular}{cccc}
\hline \multirow{2}{*}{ Parameter } & \multicolumn{3}{c}{ Magnitude of the plasticity parameters } \\
\cline { 2 - 4 } & Melnis and Knets [18] & McElhaney [1] & Crowninshield and Pope [4] \\
\hline$H[\mathrm{Mpa}]$ & 297 & 75 & 114 \\
$n p$ & 9.5 & 12.1 & 13.5 \\
$s_{y}[\mathrm{Mpa}]$ & 38.1 & 60.5 & 46.6 \\
$u_{p}[\mathrm{Mpa} \mathrm{s}]$ & $9.2 \mathrm{E}+08$ & $1.7 \mathrm{E}+09$ & $3.0 \mathrm{E}+10$ \\
\hline
\end{tabular}

Table 6. Parameters for the stress-strain tests of the remodeling component according to Figure 1.

\begin{tabular}{cccc}
\hline & & \multicolumn{3}{c}{ Magnitude of the remodeling parameter } \\
\cline { 2 - 4 } Parameter & Melnis and Knets [18] & McElhaney [1] & Crowninshield and Pope [4] \\
\hline$R\left[\mathrm{~s}^{-1}\right]$ & $2.4 \mathrm{E}-11$ & $2.1 \mathrm{E}-11$ & $3.1 \mathrm{E}-11$ \\
\hline
\end{tabular}

\section{Discussion}

Based on the results of the present study it can be concluded that the proposed model, with a suitable choice of model parameters reflecting the properties of the bone, is capable to predict the mechanical behavior of the bone. Simulations of the mechanical response, with the proposed model and calibrated model parameters, capture with good agreement the experimental stress-strain results obtained by Melnis and Knets [18], McElhaney [1], Crowninshield and Pope [4], Perren et al. [8] and Melnis et al. [27] (Figures 3-5). Bone behaves differently in tension and compression [38]. Both tension and compression can be simulated by the present model. To capture com- 
pressive or tensile behavior the model parameters have to be determined by use of compressive or tensile test respectively. In addition the proposed model, with calibrated parameters, seems to be able to capture the creep and relaxation behavior. Bone is a complex material and the diversity of the measured bone material properties might reflect the quality, porosity, and testing condition of the bone specimen. In the proposed model the individual phenomena (viscoelasticity, plasticity, relaxation, creep and remodeling) are represented with three components reflecting the behavior of bone. The viscoelastic component contains four Maxwell elements (springdashpot combinations) that capture the strain rate dependency in the stress strain tests and the viscoelastic behavior found in relaxation and creep tests. The dashpots in Maxwell elements two and three have low viscosity and do not significantly influence the stress-strain curve. The increased Young's modulus with increased strain rate is modeled, with Maxwell elements four and five. The sums of spring stiffness one to three for the individual tests [1] [4] [18] are similar to the Young's modulus presented by Johnson et al. [11]. In the proposed model the plasticity component, with Norton creep, predicts the evolution of plastic strain at different yield stress levels for different strain rates observed in experiments (Figure 2). In the prediction of stress strain behavior the plastic pad in the proposed model has one triggering stress independent of strain rate. The triggering stress is lower than the physical yield stress observed in experiments in order to capture the stress-strain at low strain rates. This might reflect the observation that bone exhibits small irreversible strain, at quite low stress levels, due to sliding between the mineral and collagen as described by Mercer et al. [13].

Iyo et al. [3] found that bone exhibits a slow relaxation in the order of $10^{6}-10^{7} \mathrm{~s}$ and a fast relaxation in the order of $10^{2} \mathrm{~s}$. In the present model the slow relaxation is governed by the Maxwell element number two in the viscoelastic component (Figure 1) and the parameter values were derived from the in vivo experiment by Perren et al. [8], resulting in a shorter relaxation time than that found by Iyo et al. [3]. The parameter values obtained from the data of Perren et al. [8] originate from in vivo tests and bone properties in live animals is probably different from those of Iyo et al. [3] investigating bone samples in vitro. Many factors, such as species, specimen type, storing and testing conditions, affect the material properties of bone [17] [18] [24] [39]. The initial drop in compression force within 14 days found by Perren et al. [8] can be explained by slow relaxation phenomena since the first registration of Perren's et al. [8] was recorded $3 \mathrm{~h}$ after the initiated loading excluding the fast relaxation. The slow relaxation has been explained by Iyo et al. [26] to be related to the structural anisotropy of bone. In the studies by Halldin et al. [40] [41], where an oversized implant was inserted in rabbit tibiae, a decrease in removal torque with longer implantation times was found. This decrease can be explained by the slow relaxation of bone. In the proposed model the parameter values in Maxwell element number three in the viscoelastic component (Figure 1) were obtained from the creep experiment of Melnis et al. [27]. The dashpot in Maxwell element three has a relaxation time of 1200 - 1300 s and differs one order of magnitude from those obtained by Iyo et al. [26]. The fast relaxation has been suggested by Iyo et al. [26] to be caused by relaxation of the collagen. Maxwell elements four and five have even shorter relaxation times of $1.4-3.3 \mathrm{~ms}$ and $1.4-21 \mu \mathrm{s}$ respectively and model the Young's modulus dependence of strain rate. The decrease in force after 14 days found by Perren et al. [8] and Blumlein et al. [31] was explained as a consequence of bone remodeling and seems to be linear over time. Therefore, in the suggested model, the remodeling component is expressed in terms of a constant strain rate reducing the stress over time. The proposed model, with calibrated parameter values, predicts with good agreement the slow relaxation and remodeling phenomena published by Perren et al. [8] (Figure 5). The total creep strain consists of two parts, one viscoelastic part that recovers when load is removed and one non-reversible viscoplastic part (Figure 1). The creep and reverse creep behavior of the proposed model, with calibrated parameters from the three different stress-strain tests [1] [4] [18], are similar to those of the creep tests performed by Melnis et al. [27] (Figure 3, Figure 4). In a constant load situation the low viscosity of the dashpots four and five makes the viscous strain occur instantly. Thus they do not contribute to creep or reversed creep strains. The high viscosity of dashpot two, with a relaxation time in the range of $3.3-4.1$ days, does not contribute significantly to the creep strain within the test time of $3.3 \mathrm{~h} \mathrm{(12,000} \mathrm{s)} \mathrm{applied} \mathrm{by} \mathrm{Melnis} \mathrm{et} \mathrm{al.} \mathrm{[27].}$ Thus the viscoelastic creep observed in Melnis et al. [27] is mainly captured by Maxwell element three as earlier discussed. The permanent deformation of bone has been suggested as a consequence of sliding between collagen and mineral that does not recover during unloading [13]. Non-recoverable creep strain in the viscoplastic component occurs when the yield condition is satisfied according to Equation (3). In the experiments of Melnis and Knets [27] non-recoverable creep strains occurred at stress levels below $40 \%$ of the ultimate stress, which is below the triggering stress of the plastic pad in the present study (Table 5). Therefore the present model is not able to capture the low non-recoverable creep strain behavior at low stress found by Melnis and Knets [27]. Melnis 
and Knets [27] indicated that a stress level around 50\% of the ultimate stress may result in constant strain rate (secondary creep). In the simulations with the present model a constant strain rate was only obtained with parameter values derived from the stress-strain tests of Melnis and Knets [18] and a constant load corresponding to $50 \%$ of ultimate strength (Figure 3(a)). This secondary creep originates from an increase in strain of the viscoplastic component, which was not obtained for the other simulations. However with an increased stress level, simulations of the other tests [1] [4] (Figure 3(b), Figure 3(c)) would have exhibited similar creep behavior as Figure 3(a).

\section{Conclusions}

Analyzing the mechanical behavior of cortical bone during different longitudinal loading situations i.e. in vitro stress-strain relationship, in vivo relaxation, in vitro creep and in vivo remodeling has led to a proposed constitutive material model with associated rheological model that consists of four different components:.

1) A viscoelastic component modeling: a) the strain rate effect on Young's modulus; b) the viscoelastic creep and c) the fast and slow relaxation. The viscoelastic component comprises 5 parts that can be tuned individually to achieve a desired model behavior.

2) A viscoplastic component triggering a) evolution of plastic strain and b) material hardening developed at different strain rates. In addition the viscoplastic component captures the secondary creep behavior.

3) A remodeling component modeling the decrease in prestress found in in vivo experiments. The decrease in prestress is interpreted as an effect of bone remodeling.

Depending on the simulation purpose the individual parts and/or components of the model may be included or excluded. The values of associated parameters should be determined by use of relevant experimental tests of bone.

\section{Acknowledgements}

This work was supported by the Swedish Research Council (621-2010-4760).

\section{References}

[1] McElhaney, J.H. (1966) Dynamic Response of Bone and Muscle Tissue. Journal of Applied Physiology, 21, 12311236.

[2] Wood, J.L. (1971) Dynamic Response of Human Cranial Bone. Journal of Biomechanics, 4, 1-12. http://dx.doi.org/10.1016/0021-9290(71)90010-8

[3] Iyo, T., Sasaki, N., Maki, Y. and Nakata, M. (2006) Mathematical Description of Stress Relaxation of Bovine Femoral Cortical Bone. Biorheology, 43, 117-132.

[4] Crowninshield, R.D. and Pope, M.H. (1974) The Response of Compact Bone in Tension at Various Strain Rates. Annals of Biomedical Engineering, 2, 217-225. http://dx.doi.org/10.1007/BF02368492

[5] Currey, J.D. (1975) The Effects of Strain Rate, Reconstruction and Mineral Content on Some Mechanical Properties of Bovine Bone. Journal of Biomechanics, 8, 81-86. http://dx.doi.org/10.1016/0021-9290(75)90046-9

[6] Carter, D.R., Caler, W.E., Spengler, D.M. and Frankel, V.H. (1981) Fatigue Behavior of Adult Cortical Bone: The Influence of Mean Strain and Strain Range. Acta Orthopaedica Scandinavica, 52, 481-490. http://dx.doi.org/10.3109/17453678108992136

[7] Sedlin, E.D. (1965) A Rheologic Model for Cortical Bone. A Study of the Physical Properties of Human Femoral Samples. Acta Orthopaedica Scandinavica, 36, 1-77. http://dx.doi.org/10.3109/ort.1965.36.suppl-83.01

[8] Perren, S.M., Huggler, A., Russenberger, M., Allgower, M., Mathys, R., Schenk, R., Willenegger, H. and Muller, M.E. (1969) The Reaction of Cortical Bone to Compression. Acta Orthopaedica Scandinavica, S125, 19-29.

[9] Reilly, D.T. and Burstein, A.H. (1974) Review Article. The Mechanical Properties of Cortical Bone. The Journal of bone and Joint Surgery, 56, 1001-1022.

[10] Reilly, D.T. and Burstein, A.H. (1975) The Elastic and Ultimate Properties of Compact Bone Tissue. Journal of Biomechanics, 8, 393-405. http://dx.doi.org/10.1016/0021-9290(75)90075-5

[11] Johnson, T.P., Socrate, S. and Boyce, M.C. (2010) A Viscoelastic, Viscoplastic Model of Cortical Bone Valid at Low and High Strain Rates. Acta Biomaterialia, 6, 4073-4080. http://dx.doi.org/10.1016/j.actbio.2010.04.017

[12] Garcia, D., Zysset, P.K., Charlebois, M. and Curnier, A. (2009) A Three-Dimensional Elastic Plastic Damage Consti- 
tutive Law for Bone Tissue. Biomechanics and Modeling in Mechanobiology, 8, 149-165. http://dx.doi.org/10.1007/s10237-008-0125-2

[13] Mercer, C., He, M.Y., Wang, R. and Evans, A.G. (2006) Mechanisms Governing the Inelastic Deformation of Cortical Bone and Application to Trabecular Bone. Acta Biomaterialia, 2, 59-68. http://dx.doi.org/10.1016/j.actbio.2005.08.004

[14] Shunmugasamy, V.C., Gupta, N. and Coelho, P.G. (2010) High Strain Rate Response of Rabbit Femur Bones. Journal of Biomechanics, 43, 3044-3050. http://dx.doi.org/10.1016/j.jbiomech.2010.06.034

[15] Rho, J.Y., Kuhn-Spearing, L. and Zioupos, P. (1998) Mechanical Properties and the Hierarchical Structure of Bone. Medical Engineering \& Physics, 20, 92-102. http://dx.doi.org/10.1016/S1350-4533(98)00007-1

[16] Hamed, E., Novitskaya, E., Li, J., Chen, P.Y., Jasiuk, I. and McKittrick, J. (2012) Elastic Moduli of Untreated, Demineralized and Deproteinized Cortical Bone: Validation of a Theoretical Model of Bone as an Interpenetrating Composite Material. Acta Biomaterialia, 8, 1080-1092. http://dx.doi.org/10.1016/j.actbio.2011.11.010

[17] Currey, J.D. (2004) Tensile Yield in Compact Bone Is Determined by Strain, Post-Yield Behaviour by Mineral Content. Journal of Biomechanics, 37, 549-556. http://dx.doi.org/10.1016/j.jbiomech.2003.08.008

[18] Melnis, A.É. and Knets, I.V. (1982) Effect of the Rate of Deformation on the Mechanical Properties of Compact Bone Tissue. Mechanics of Composite Materials, 18, 358-363. http://dx.doi.org/10.1007/BF00604319

[19] Pithioux, M., Subit, D. and Chabrand, P. (2004) Comparison of Compact Bone Failure under Two Different Loading Rates: Experimental and Modelling Approaches. Medical Engineering and Physics, 26, 647-653. http://dx.doi.org/10.1016/j.medengphy.2004.05.002

[20] Hansen, U., Zioupos, P., Simpson, R., Currey, J.D. and Hynd, D. (2008) The Effect of Strain Rate on the Mechanical Properties of Human Cortical Bone. Journal of Biomechanical Engineering, 130, 011011-011018. http://dx.doi.org/10.1115/1.2838032

[21] Wright, T.M. and Hayes, W.C. (1976) Tensile Testing of Bone over a Wide Range of Strain Rates: Effects of Strain Rate, Microstructure and Density. Medical \& Biological Engineering, 14, 671-680. http://dx.doi.org/10.1007/BF02477046

[22] Currey, J.D. (1988) Strain Rate and Mineral Content in Fracture Models of Bone. Journal of Orthopaedic Research, 6, 32-38. http://dx.doi.org/10.1002/jor.1100060105

[23] Currey, J.D. (1988) The Effect of Porosity and Mineral Content on the Young's Modulus of Elasticity of Compact Bone. Journal of Biomechanics, 21, 131-139. http://dx.doi.org/10.1016/0021-9290(88)90006-1

[24] McCalden, R.W., McGeough, J.A., Barker, M.B. and Court-Brown, C.M. (1993) Age-Related Changes in the Tensile Properties of Cortical Bone. The Relative Importance of Changes in Porosity, Mineralization, and Microstructure. The Journal of Bone and Joint Surgery, American Volume, 75, 1193-1205.

[25] Zioupos, P., Hansen, U. and Currey, J.D. (2008) Microcracking Damage and the Fracture Process in Relation to Strain Rate in Human Cortical Bone Tensile Failure. Journal of Biomechanics, 41, 2932-2939. http://dx.doi.org/10.1016/j.jbiomech.2008.07.025

[26] Iyo, T., Maki, Y., Sasaki, N. and Nakata, M. (2004) Anisotropic Viscoelastic Properties of Cortical Bone. Journal of Biomechanics, 37, 1433-1437. http://dx.doi.org/10.1016/j.jbiomech.2003.12.023

[27] Melnis, A.É., Knets, I.V. and Moorlat, P.A. (1979) Deformation Behavior of Human Compact Bone Tissue upon Creep under Tensile Testing. Mechanics of Composite Materials, 15, 574-579. http://dx.doi.org/10.1007/BF00605581

[28] Melnis, A.É. and Knets, I.V. (1982) Age-Related Changes in the Tensile Creep Properties of Human Compact Bone Tissue. Mechanics of Composite Materials, 17, 495-501. http://dx.doi.org/10.1007/BF00605920

[29] Knet-s, I.V. and Vilks, Y.K. (1975) Creep of Compact Human Bony Tissue under Tension. Polymer Mechanics, 11, 543-547. http://dx.doi.org/10.1007/BF00856779

[30] Fondrk, M., Bahniuk, E., Davy, D.T. and Michaels, C. (1988) Some Viscoplastic Characteristics of Bovine and Human Cortical Bone. Journal of Biomechanics, 21, 623-630. http://dx.doi.org/10.1016/0021-9290(88)90200-X

[31] Blumlein, H., Cordey, J., Schneider, U.A., Rahn, B.A. and Perren, S.M. (1977) Long-Term Measurements of Axial Force of Screws in Vivo for Osteosynthesis-Langzeitmessung der Axialkraft von Knochenschrauben in Vivo. Zeitschrift Fur Orthopadie Und Ihre Grenzgebiete, 115, 603-604.

[32] Cordey, J., Blumlein, H., Ziegler, W. and Perren, S.M. (1976) Study of the Behavior in the Course of Time of the Holding Power of Cortical Screws in Vivo. Acta Orthopaedica Belgica, 42, 75-87.

[33] Roberts, W.E., Turley, P.K., Brezniak, N. and Fielder, P.J. (1987) Implants: Bone Physiology and Metabolism. CDA Journal California Dental Association, 15, 54-61.

[34] Perzyna, P. (1966) Fundamental Problems in Viscoplasticity. Advances in Applied Mechanics, 9, 243-377.

[35] Perzyna, P. (1971) Thermodynamic Theory of Viscoplasticity. Advances in Applied Mechanics, 11, 313-354. 
[36] Ottosen, N.S. and Ristinmaa, M. (2005) The Mechanics of Constitutive Modeling. Elsevier, Amsterdam.

[37] Norton, F.H. (1929) The Creep of Steel at High Temperatures. McGraw-Hill Book Company, New York.

[38] Garcia, D. (2006) Elastic Plastic Damage Laws for Cortical Bone. Ph.D. Dissertation, Thèse No. 3435, Ecole Polytechnique Fédérale De Lausanne, Lusanne.

[39] Melnis, A.É., Kregers, A.F. and Villerush, K.K. (1982) An Evaluation of Some Factors Affecting the Creep Properties of Human Compact Bone Tissue. Mechanics of Composite Materials, 17, 711-715. http://dx.doi.org/10.1007/BF00605058

[40] Halldin, A., Jimbo, R., Johansson, C.B., Wennerberg, A., Jacobsson, M., Albrektsson, T. and Hansson, S. (2011) The Effect of Static Bone Strain on Implant Stability and Bone Remodeling. Bone, 49, 783-789. http://dx.doi.org/10.1016/j.bone.2011.07.003

[41] Halldin, A., Jimbo, R., Johansson, C.B., Wennerberg, A., Jacobsson, M., Albrektsson, T. and Hansson, S. (2014) Implant Stability and Bone Remodeling after 3 and 13 Days of Implantation with an Initial Static Strain. Clinical Implant Dentistry and Related Research, 16, 383-393. http://dx.doi.org/10.1111/cid.12000 
Scientific Research Publishing (SCIRP) is one of the largest Open Access journal publishers. It is currently publishing more than 200 open access, online, peer-reviewed journals covering a wide range of academic disciplines. SCIRP serves the worldwide academic communities and contributes to the progress and application of science with its publication.

Other selected journals from SCIRP are listed as below. Submit your manuscript to us via either submit@scirp.org or Online Submission Portal.
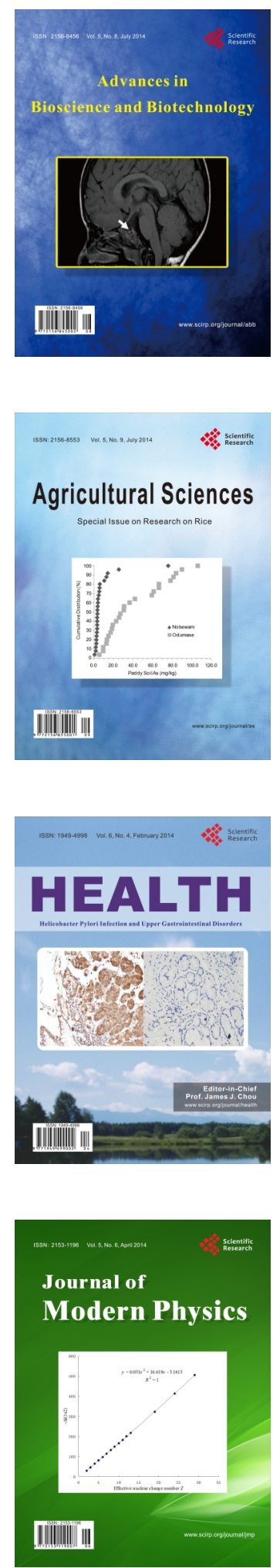
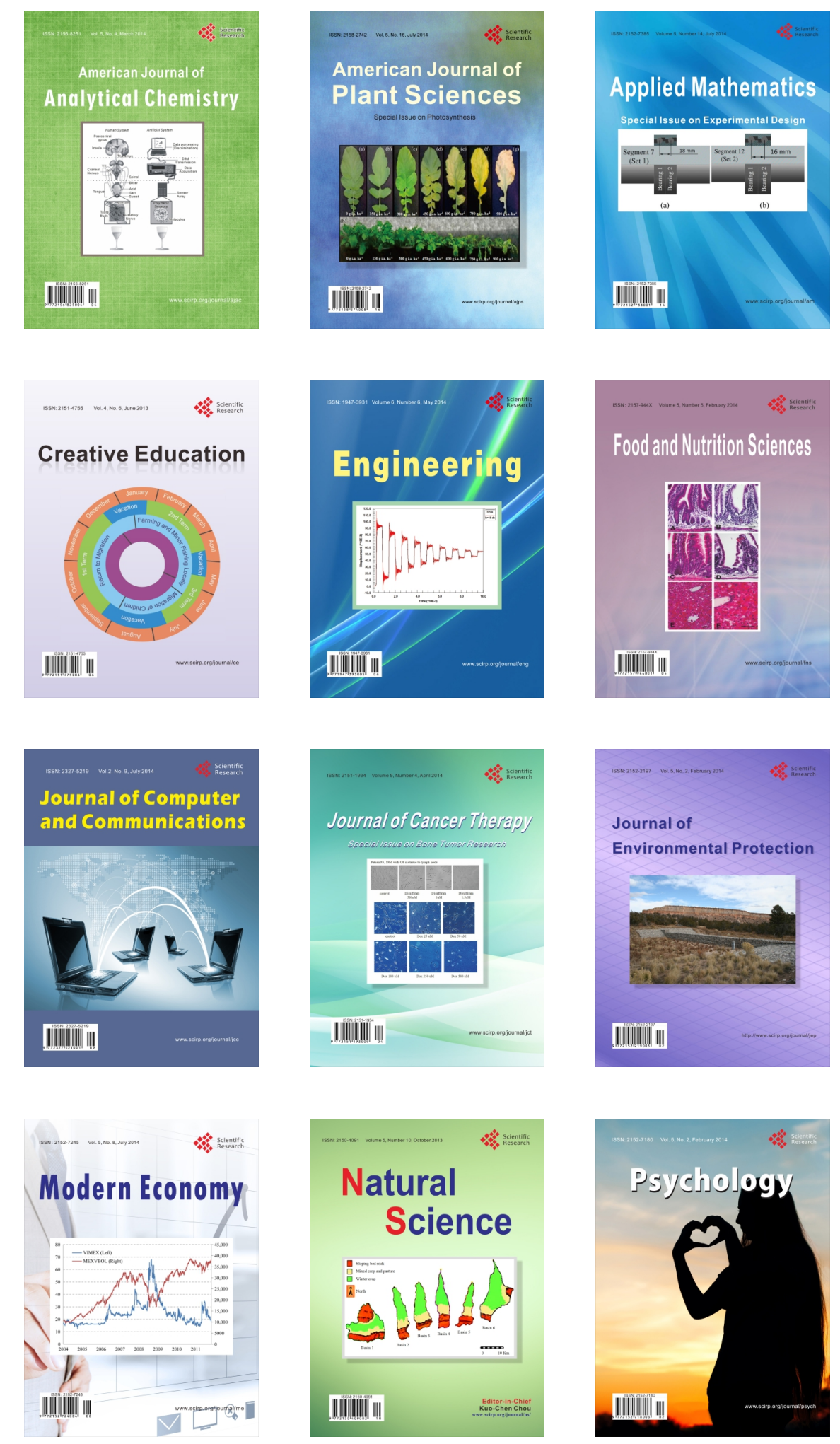